\title{
PERKEMBANGAN KONSEP DAN ALAT UKUR HARAPAN DALAM PENINGKATAN KUALITAS HIDUP PASIEN PENYAKIT GINJAL TAHAP AKHIR (PGTA): ANALYTIC REVIEW
}

\author{
Nining Puji Astuti*, Untung Sujianto**, Henni Kusuma ${ }^{* * *}$ \\ ${ }^{*}$ Departemen Ilmu Keperawatan, Fakultas Kedokteran, Universitas Diponegoro, Indonesia, email: \\ nining285@gmail.com \\ ${ }^{* *)}$ Departemen Ilmu Keperawatan, Fakultas Kedokteran, Universitas Diponegoro, Indonesia, email: \\ untung71@yahoo.co.id \\ ${ }^{* * *}$ Departemen Ilmu Keperawatan, Fakultas Kedokteran, Universitas Diponegoro, Indonesia, email: \\ henni.kusuma@fk.undip.ac.id \\ Corresponding Author : nining285@gmail.com
}

\begin{abstract}
Abstrak
Pemaparan konsep harapan sebagai ilmu pengetahuan telah dikembangkan sejak dahulu, namun pelaksanaan pengkajian dan intervensi peningkatan harapan pada praktik klinik keperawatan masih sangat minim dilakukan. Perlu pemahaman mengenai konsep dan pengembangan alat ukur harapan pada pasien Penyakit Ginjal Tahap Akhir (PGTA) demi meningkatkan kualitas hidup PGTA. Tujuan analytic review ini untuk mengidentifikasi konsep harapan berdasarkan definisi dan instrumen yang dapat digunakan untuk mengukur harapan PGTA, serta mengidentifikasi faktor yang mempengaruhi harapan PGTA. Metode pencarian melalui database Pubmed, Biomedical Journal, dan Google Scholar dengan kata kunci hope, end stage renal disease, chronic kidney diseases, dan quality of life. Kriteria inklusi pencarian dalam pembuatan analytic review ini yaitu artikel dalam Bahasa Inggris, full text, dipublikasikan tahun 2000-2019 dan menggunakan harapan sebagai tema utama dalam pembahasan. Sejumlah 9 artikel jurnal digunakan dalam pembahasan studi ini. Harapan didefinisikan sebagai kekuatan dalam diri individu yang membantu pasien keluar dari zona sakitnya dan meningkatkan derajat kesehatannya. Alat ukur yang dapat dipakai antara lain Herth Hope Index, The Trait Hope Scale, Adult Hope Scale, Miller Hope Scale, Basic Hope Inventory. Level harapan PGTA dipengaruhi oleh banyak faktor baik dari internal ataupun eksternal yang muncul dari lingkungan. Harapan dapat dilihat dari banyak perspektif namun fokus utama harapan adalah tujuan akan masa depan. Konsep harapan merupakan konsep ilmiah yang dapat dijelaskan secara ilmiah dan dapat diukur.
\end{abstract}

Kata kunci: penyakit ginjal kronik, harapan, kualitas hidup

\section{PENDAHULUAN}

Hemodialisis merupakan salah satu alternatif terapi yang bisa dilakukan oleh penderita Penyakit Ginjal Tahap Akhir (PGTA). Hemodialisis harus dilakukan seumur hidup oleh pasien untuk mempertahankan homeostasis ginjal dan mempertahankan hidup penderita. Seorang PGTA yang menjalani hemodialisis harus mentaati jadwal hemodialisis yang sudah ditentukan oleh RS, Astuti, Sujianto, Kusuma / Perkembangan Konsep dan Alat Ukur Harapan dalam ... Page 41 of 51 
Jurnal IImu Keperawatan Medikal Bedah 2 (2), November 2019, 1-51

ISSN 2338-2058 (print), ISSN 2621-2986 (online)

mentaati diit makanan dan cairan, patuh kepada pengobatan dan terus menjaga pola hidup yang sehat. Sebagai salah satu penyakit irreversible dengan pengobatan seumur hidup, banyak dampak baik fisik, mental, ekonomi, psikologis, maupun sosial yang harus dijalani oleh seorang PGTA (Bayoumi \& Alwakeel, 2012; Ghadam et al., 2015). Penderita PGTA juga harus kehilangan pekerjaan, pasangan, mengalami disfungsi seksual, merasa dikucilkan dari pergaulan yang membuat PGTA terpuruk sehingga PGTA merasa kehilangan harapan dan tidak mampu merasakan kebahagiaan dalam hidupnya. Keterpurukan karena merasa kehilangan harapan dalam hidup PGTA dapat menimbulkan dampak negatif pada PGTA. Salah satu dampaknya adalah penderita tidak mau melanjutkan pengobatan yang bisa saja menimbulkan kematian PGTA. Hal tersebut seperti penelitian yang telah dilakukan Davison dan Simpson (2006) dimana menyebutkan bahwa hilangnya harapan sebagai salah satu motivasi PGTA menyebabkan 15-29 \% penderita PGTA meninggal dunia karena tidak mau melanjutkan therapi hemodialisis.

Harapan merupakan sumber kekuatan internal individu dan motivator utama untuk meningkatkan kualitas dan vitalitas hidup. Harapan berhubungan dengan ekspektasi positif terkait masa depan. Harapan memampukan individu untuk bertahan dan menemukan jalan untuk keluar dari masalah (Hendricks et al., 2005; Abdi \& Asadi-Lari, 2011). Harapan disebut sebagai faktor psikologis yang dapat mempengaruhi kemampuan pasien untuk melakukan perawatan diri, adaptasi terhadap penyakit dan perilaku positif menjaga kesehatan (Poorgholami, Abdollahifard, Zamani, Jahromi, \& Jahromi, 2015).

Dalam keperawatan, harapan mulai diperkenalkan sejak tahun 1965 (Hendricks et al., 2005). Harapan sangat diperlukan oleh pasien terutama dalam menghadapi penyakit kronis dan ketidakpastian prognosis penyakit. Miller (1989) menyatakan bahwa harapan merupakan hal penting untuk membentuk mekanisme koping yang baik sehingga pasien dapat melawan stress psikologisnya, mengatur emosi, menghadapi krisis, menerima perubahan fugsional, menghadapi depresi yang timbul akibat penyakit, dan lain-lain (Herth, 2014). Tindakan keperawatan untuk mengkaji dan memberikan intervensi keperawatan terkait harapan sangat perlu dilakukan oleh perawat untuk mengatasi masalah keperawatan hopeless. Pasien tidak hanya membutuhkan dukungan secara fisik saja namun dukungan psikologis. Peningkatan harapan juga merupakan faktor utama dalam peningkatan kualitas hidup penderita PGTA. Penelitian mengenai harapan sangat penting dilakukan untuk meningkatkan dukungan secara komprehensif meliputi unsur Astuti, Sujianto, Kusuma / Perkembangan Konsep dan Alat Ukur Harapan dalam ... Page 42 of 51 
Jurnal Ilmu Keperawatan Medikal Bedah 2 (2), November 2019, 1-51

ISSN 2338-2058 (print), ISSN 2621-2986 (online)

biologis, psikologis, sosial, dan spiritual pada penderita PGTA. Sehingga diperlukan pemahaman mengenai konsep harapan oleh perawat karena harapan merupakan konsep yang bisa diterima dan rasional. Studi ini dilakukan dengan tujuan untuk mengidentifikasi teori dan definisi operasional yang digunakan dalam mendefinisikan harapan pasien PGTA dan mengidentifikasi penerapan terapi harapan pada pasien PGTA.

\section{METODE PENELITIAN}

Penelitian ini merupakan analytic review dengan 9 artikel jurnal sebagai literatur. Metode pencarian dilakukan melalui database PUBMED, Google Scholar, dan Biomedical Journal dengan kata kunci hope, end stage renal disease, chronic kidney diseases, dan quality of life. Artikel yang digunakan merupakan artikel dengan masa publikasi tahun 2000-2019, artikel menggunakan bahasa Inggris, full text, dan menggunakan intervensi terapi hope sebagai bahasan utama. Berdasarkan pencarian dari 3 database tersebut maka ditemukan 170 artikel jurnal. Dari 170 artikel kemudian dilakukan seleksi dari duplikasi, judul, abstrak, dan isi jurnal maka diperoleh 9 artikel jurnal yang digunakan dalam review analisis ini. Sejumlah 9 artikel jurnal ini kemudian dianalisa menggunakan teknik PICO (Problem, Intervention, Comparison, \& Outcome). Metode seleksi literatur dapat dibaca pada gambar 1. 
Jurnal IImu Keperawatan Medikal Bedah 2 (2), November 2019, 1-51

ISSN 2338-2058 (print), ISSN 2621-2986 (online)

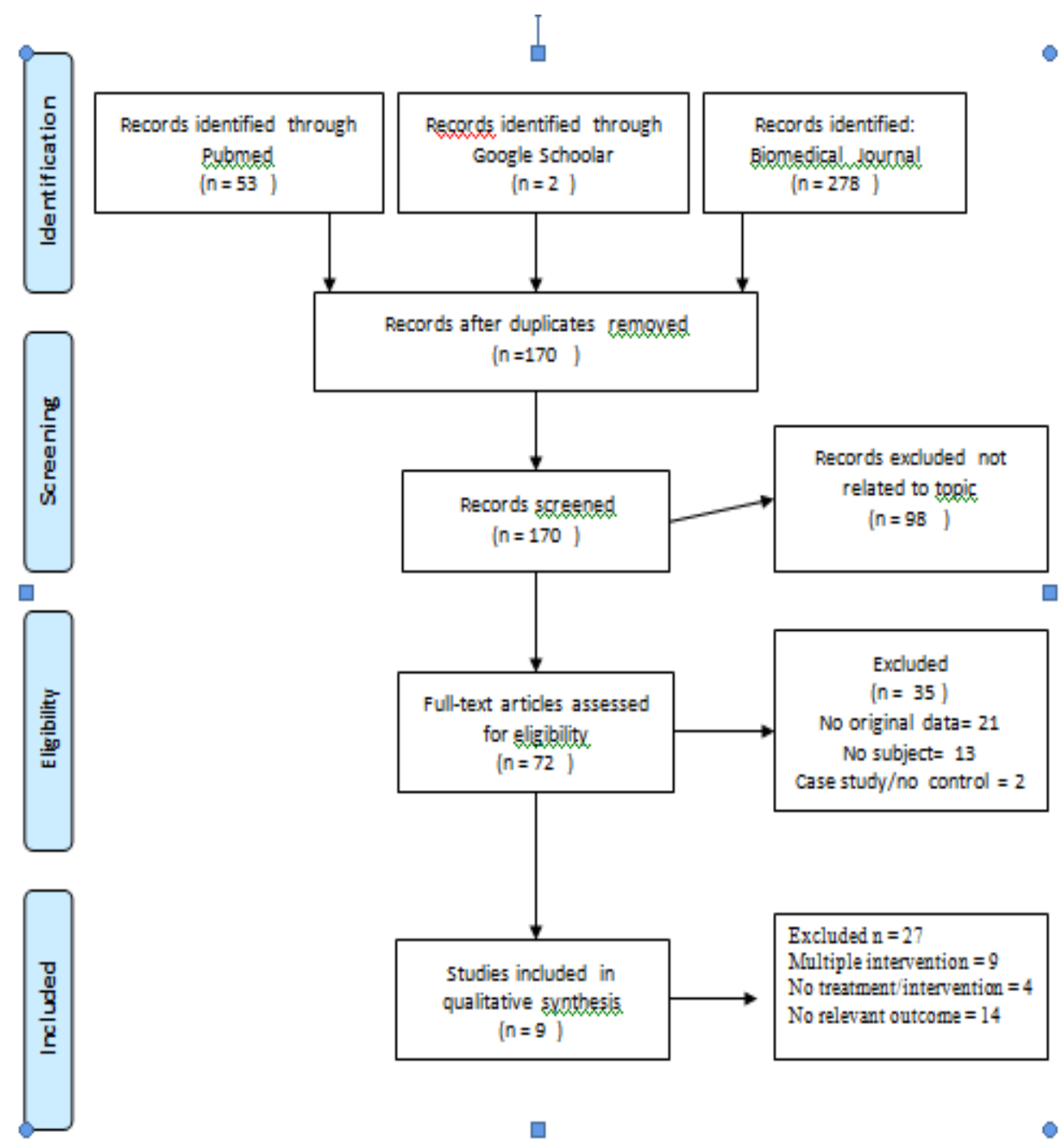

Gambar 1. Diagram Seleksi Literatur

\section{HASIL DAN PEMBAHASAN}

Melalui metode pencarian maka ditemukan 170 artikel dan 9 artikel dipilih sesuai dengan kriteria inklusi. Sejumlah 2 artikel menggunakan metode uji korelasi, 3 artikel menggunakan metode cross sectional, 1 artikel kualitatif dengan wawancara mendalam, 2 artikel eksperimen kuasi, dan 1 artikel Randomized Controlled Trial.

\section{1) Eksperiemen Kuasi}

Sejumlah 2 artikel dengan pendekatan eksperimen kuasi dilakukan dengan tujuan untuk menguji pengaruh sebuah intervensi terhadap level harapan pasien. Salah satu artikel memaparkan Astuti, Sujianto, Kusuma / Perkembangan Konsep dan Alat Ukur Harapan dalam ... Page 44 of 51 
Jurnal IImu Keperawatan Medikal Bedah 2 (2), November 2019, 1-51

ISSN 2338-2058 (print), ISSN 2621-2986 (online)

mengenai pengaruh Cognitive Existential Group Therapy, jumlah partisipan 22 pasien perempuan, intervensi dilakukan selama 3 bulan. Tindakan dilakukan dengan 12 sesi selama masing-masing sesi adalah 90 menit dan dilakukan dua kali selama satu minggu. Hasil studi signifikan untuk meningkatkan level harapan pasien PGTA dengan $\mathrm{p}<0.001$. Artikel menjelaskan bahwa harapan dapat dipengaruhi oleh emosi, tingkat pengetahuan, motivasi dan tingkat kepercayaan dari pasien sehingga diperlukan kajian mengenai tingkat pengetahuan pasien dari masa lampau sampai saat pasien menghadapi kondisi sakitnya. Cognitive Existential Group Therapy merupakan metode kombinasi antara mengkaji pengetahuan dengan mengevaluasi penyelesaian masalah pasien untuk meningkatkan koping sehingga pasien mampu menghadapi perasaan kesendiriannya dan menghadapi stressor selama pasien menjalani pengobatan (Bahmani, Najjar, Sayyah, Shafi-Abadi, \& Kashani, 2015).

Artikel kedua membahas mengenai efek manajemen stress terhadap tingkat harapan pasien. Intervensi dilakukan pada 50 pasien PGTA dengan membagi sample menjadi kelompok kecil yang terdiri dari 5-8 pasien setiap kelompok. Tindakan dilakukan selama 5 sesi dan setiap sesi adalah 60 menit selama 8 minggu. Berdasarkan artikel tersebut didapatkan hasil bahwa harapan dipengaruhi oleh kecemasan, depresi, koping, emosi negatif, efikasi diri, komplikasi fisik dan psikososial pasien PGTA. Harapan merupakan salah satu bagian dari 3 subjek utama kesehatan mental, emosional dan kesehatan pada PGTA (Poorgholami, Abdollahifard, Zamani, Jahromi, \& Jahromi, 2015).

\section{2) Randomized Controlled Trial (RCT)}

Sejumlah 1 artikel dengan metode RCT dengan melakukan tindakan melalui pendidikan perawatan diri dengan atau tanpa follow up berpengaruh terhadap peningkatan level harapan pasien PGTA. Sampel penelitian 75 pasien dan dibagi kedalam 3 grup $(n=25)$ dengan melakukan pendidikan kesehatan mengenai perawatan diri dengan follow up dengan telepon. Hasilnya level harapan pasien HD meningkat dengan signifikansi $\mathrm{p}=0.001$. Tingkat pengetahuan kemampuan perawatan diri dapat meningkatkan penerimaan diri pasien terhadap kondisinya, mengurangi stress fisik dan psikologisnya sehingga mampu meningkatkan harapan pasien. Hilangnya harapan memberi dampak terjadinya penurunan nafsu makan, penurunan berat badan, penurunan kemampuan untuk adaptasi menuju perilaku positif, penolakan pengobatan, ketidakmampuan 
Jurnal IImu Keperawatan Medikal Bedah 2 (2), November 2019, 1-51

ISSN 2338-2058 (print), ISSN 2621-2986 (online)

mempelajari hal baru, kecemasan dan ketidakmampuan (Poorgholami, Mansoori, Montaseri, \& Najafi, 2016).

\section{3) Studi Korelasi}

Sejumlah 2 studi korelasi membahas mengenai harapan dan tingkat spiritual serta inovasi transplantasi ginjal terhadap peningkatan harapan pasien PGTA. Terdapat hubungan positif antara harapan dengan tingkat spiritualitas melalui uji koefisien korelasi Pearson $\mathrm{p}<0.001$. Harapan merupakan faktor esensial kehidupan manusia dan memiliki kekuatan untuk meningkatkan dukungan, motivasi, dan koping. Spiritual memiliki keterikatan dengan harapan dikarenakan dimensi spiritual sangat erat kaitannya dengan makna hidup dan spiritual merupakan sumber harapan ketika coping kita menurun saat menghadapi masa sakit (Ottaviani et al., 2014).

Transplantasi ginjal menjadi salah satu upaya terapi PGTA yang lebih bersahabat dalam meningkatkan kualitas hidup pasien. Namun, pada studi yang dilakukan oleh Zegarow, Jankowska, Sańko-Resmer, Durlik, Grzeszczyk, \& Pączek (2014) disebutkan bahwa tidak ada perbedaan level harapan pasien PGTA yang menjalani hemodialisis ataupun transplantasi. Skor harapan pasien hemodialisis diukur dengan BHI (Basic Hope Inventory) pasien hemodialisis adalah 29.0 (medium) sedang skor harapan pasien transplantasi ginjal 29.3 (medium). Tidak adanya perbedaan skor harapan yang signifikan tersebut diperkirakan karena dampak stress psikologis pada kedua kondisi tersebut hampir sama yaitu 25-29\% pasien dengan hemodialisis dan transplantasi dilaporkan mengalami stress psikologi berupa depresi (Zegarow, Jankowska, Sańko-Resmer, Durlik, Grzeszczyk, \& Pączek, 2014).

\section{4) Cross Sectional}

PGTA yang menjalani hemodialisis harus menggantungkan hidupnya pada mesin dialisis. Hal ini menyebabkan penurunan pada kualitas hidup dan penurunan level harapan PGTA. Studi Orlandi menyebutkan bahwa evaluasi level harapan pada 50 pasien hemodialisis pada kategori sedang dengan nilai 36.20 menggunakan Herth Hope Scale (HHS) (Orlandi, Pepino, Pavarini, dos Santos, \& de Mendiondo, 2012). Faktor dominan yang mempengaruhi harapan adalah diri pribadi pasien, lingkungan, dan tujuan. Faktor dari dalam diri pribadi meliputi tingkat religiusitas, semangat, dukungan sosial, tingkat pendapatan/ekonomi, pengalaman, keluarga, dan hasil pemeriksaan kesehatan (Malik \& Mazahir, 2015). 
Jurnal IImu Keperawatan Medikal Bedah 2 (2), November 2019, 1-51

ISSN 2338-2058 (print), ISSN 2621-2986 (online)

Pada kondisi kronis, pasien memerlukan harapan sebagai motivasi dalam mencapai tujuan yang pasti. Berdasarkan model regresi, faktor prediktor yang dapat meningkatkan outcome positif pasien PGTA antara lain kecemasan, depresi, efek dan gejala PGTA, kesehatan mental. Harapan terbukti merupakan faktor prediktor independent yang ikut berperan dalam meningkatan outcome positif demi tercapainya kualitas hidup yang baik pada PGTA (Billington, Simpson, Unwin, Bray, \& Giles, 2008).

\section{5) Qualitative Deep Interview}

Harapan merupakan suatu hal yang personal, sangat individual, kompleks dan beragam. Harapan berhubungan dengan diri pribadi pasien, lingkungan, setting tujuan, dan perencanaan mengenai outcome positif pasien. Harapan membantu PGTA untuk menentukan perencanaan kesehatan yang lebih baik, merencanakan masa depan yang lebih baik, membantu menentukan tujuan hidup, berperan dalam pencapaian kesejahteraan pada masa akhir kehidupan. Kestabilan harapan pasien ditentukan oleh informasi kesehatan yang diterima PGKTA, kekuatan, dan hubungan personal pasien dengan orang lain dan tenaga kesehatan (Davison \& Simpson, 2006).

\section{Definisi Harapan}

Harapan menurut kamus besar bahasa Indonesia merupakan suatu bentuk sesuatu yang bisa diharapkan dan merupakan sebuah keinginan supaya menjadi kenyataan (KBBI, 2019). Harapan (hope) sebagai kata benda menurut kamus Oxford merupakan sebuah kepercayaan yang selalu berhubungan dengan ekspektasi yang positif terkait hal baik di masa depan ("Hope | Definition of hope in English by Oxford Dictionaries, ” n.d.).

\section{Definisi Teoritis Harapan}

Harapan merupakan fokus seseorang kepada sebuah tujuan dalam hidupnya (Herth, 2014). Harapan selalu berhubungan dengan fokus diri dan dipengaruhi oleh dukungan sosial dari sekitar. Harapan tidak hanya berfokus pada diri sendiri, harapan dapat digambarkan sebagai harapan untuk orang lain (Day, 1969 dalam Abdi, N., \& Asadi-Lari, 2011). McGeer (2004, dalam Herth, 2014) menyatakan bahwa kunci sebuah harapan merupakan pandangan atau ekspektasi positif tentang masa depan yang berfokus pada diri sendiri dan orang lain. Sejalan dengan Day (1969 dalam Abdi, N., \& Asadi-Lari, 2011), beliau menyatakan bahwa harapan untuk diri sendiri, orang lain, sosial 
Jurnal IImu Keperawatan Medikal Bedah 2 (2), November 2019, 1-51

ISSN 2338-2058 (print), ISSN 2621-2986 (online)

digambarkan ke dalam hal-hal baik terkait pandangan individu untuk masa yang akan datang (Howell \& Larsen, 2015).

\section{Harapan dalam PGTA}

Harapan dalam sisi keperawatan diartikan sebagai harapan perawat sebagai pemberi asuhan keperawatan kepada kliennya (Frank, 1968 dalam Herth, 2014). Konteks ini dirasa penting sebagai bentuk kepedulian pemberi asuhan kepada adanya perubahan teraupetik pada sisi pasien (Howell \& Larsen, 2015). Beberapa penelitian mengenai harapan dalam sisi keperawatan telah dilakukan pada pasien dengan lingkungan dan kondisi yang berbeda-beda. Harapan dipandang sebagai komponen penting dalam meningkatkan mekanisme koping pasien terutama pada pasien kronis seperti PGTA (Poorgholami, Abdollahifard, Zamani, Jahromi, \& Jahromi, 2015). Harapan juga dipandang sebagai prediktor kuat dalam hal psikologis yang mampu mengatasi masalah kecemasan, depresi, mood, koping, efek samping dari HD, dan masalah-masalah psikologis lain yang akan mengganggu kualitas hidup pasien HD (Billington, Simpson, Unwin, Bray, \& Giles, 2008). Di dalam harapan terdapat proses kognitif yang akan membentuk suatu tujuan yang berhubungan dengan pathway dan agency. Pathway merupakan pandangan bagaimana individu mampu merencakan cara mencapai tujuannya sedangkan agency merupakan bentuk upaya seseorang dalam membentuk tujuannya (Malik \& Mazahir, 2015).

Tabel 1: Harapan pada Penyakit Ginjal Tahap Akhir

\begin{tabular}{|c|c|}
\hline Penulis & Definisi \\
\hline Bahmani et al, 2015 & $\begin{array}{l}\text { Harapan merupakan komponen psikologis yang dapat } \\
\text { dipengaruhi oleh emosi, tingkat pengetahuan, motivasi } \\
\text { dan kepercayaan antara perawat dan pasien. }\end{array}$ \\
\hline Poorgholami et al, 2015 & $\begin{array}{l}\text { Harapan adalah bagian dari kesehatan mental, } \\
\text { emosional dan kesehatan yang dapat terbentuk dengan } \\
\text { manajemen stress yang baik pada PGTA. }\end{array}$ \\
\hline Poorgholami et al, 2016 & $\begin{array}{l}\text { Harapan adalah kondisi psikologis yang berperan } \\
\text { penting dalam peningkatan kemampuan perawatan diri } \\
\text { PGTA. }\end{array}$ \\
\hline Ottaviani, 2014 & $\begin{array}{l}\text { Harapan merupakan faktor esensial yang ada pada } \\
\text { PGTA yang sangat brhubungan dengan tingkat } \\
\text { spiritual PGTA. }\end{array}$ \\
\hline Zegarow et al, 2014 & $\begin{array}{l}\text { Harapan merupakan proses antisipasi terhadap depresi } \\
\text { dan beban psikologis yang tinggi pada PGTA. }\end{array}$ \\
\hline Malik \& Mazahir, 2015 & $\begin{array}{l}\text { Harapan merupakan kekuatan psikologis yang } \\
\text { bersumber dari dalam diri individu dan dipengaruhi } \\
\text { oleh diri individu itu sendiri. }\end{array}$ \\
\hline
\end{tabular}

Astuti, Sujianto, Kusuma / Perkembangan Konsep dan Alat Ukur Harapan dalam ... Page 48 of 51 
Jurnal IImu Keperawatan Medikal Bedah 2 (2), November 2019, 1-51

ISSN 2338-2058 (print), ISSN 2621-2986 (online)

\section{Alat Ukur Harapan}

Beberapa studi menjelaskan bahwa harapan pasien dapat dipertahankan ketika pasien tetap dapat menghargai dirinya sendiri. Harapan juga dapat dipertahankan dengan cara mengkomunikasikan prognosis dan pengobatan kepada pasien dan keluarga. Dalam perkembangannya, terdapat beberapa alat ukur yang dikembangkan untuk mengukur harapan. Alat ukur harapan yang digunakan pada pasien penyakit ginjal tahap akhir antara lain:

Tabel 2: Alat Ukur Harapan pada Penyakit Ginjal Tahap Akhir

\begin{tabular}{|c|c|c|}
\hline Skala & Deskripsi & Reliabilitas dan Validitas \\
\hline $\begin{array}{l}\text { Herth Hope Index } \\
(\mathrm{HHI})\end{array}$ & $\begin{array}{l}\text { a. } 12 \text { item. } \\
\text { b. Skoring dengan } 4 \text { poin skala } \\
\text { likert, } 1 \text { = sangat tidak setuju } \\
\text { dan } 4 \text { adalah sangat setuju. } \\
\text { c. Total skor } 12-48 \text { dengan skor } \\
\text { tertinggi menggambarkan } \\
\text { harapan yang tinggi. }\end{array}$ & $\begin{array}{ll}\text { a. } & \text { Chronbach alpha } \\
& \text { koefisien 0,97, test } \\
& \text { retest ( } 2 \text { minggu })= \\
& 0,91 \\
\text { b. } & \text { Kriteria validitas } 0,84- \\
& 0,92\end{array}$ \\
\hline The Trait Hope Scale & $\begin{array}{l}\text { a. } 12 \text { item } \\
\text { b. } 4 \text { poin skala likert dengan } \\
1=\text { sangat salah dan } 4=\text { sangat } \\
\text { benar. } \\
\text { c. Range skor } 8-64 \text { dengan skor } \\
\text { tertinggi menggambarkan } \\
\text { level harapan tertinggi. }\end{array}$ & $\begin{array}{ll}\text { a. } & \text { Chronbach alpha } 0,74- \\
& 0,78 \\
\text { b. } & \text { Test retest } \mathrm{r}=0,73-0,82 \\
& (10 \text { minggu })\end{array}$ \\
\hline Adult Hope Scale & $\begin{array}{l}\text { a. } 12 \text { item } \\
\text { b. } 8 \text { poin skala likert dari sangat } \\
\text { salah sampai sangat benar. }\end{array}$ & Chronbach alpha 0,83 \\
\hline Miller Hope Scale & $\begin{array}{l}\text { a. } 48 \text { Item } \\
\text { b. Skor tiap item adalah 1-5 } \\
\text { c. Total skor } 48-240\end{array}$ & Chronbach alpha 0,92 \\
\hline Basic Hope Inventory & $\begin{array}{l}\text { a. } 12 \text { statemen } \\
\text { b. } 5 \text { poin kala grafik }\end{array}$ & Chronbach alpha 0,62 \\
\hline
\end{tabular}

\section{KESIMPULAN}

Harapan dalam kesehatan berhubungan dengan keinginan untuk sembuh dan terbebas dari penyakit. Harapan merupakan domain dari hubungan dan kasih sayang yaitu harapan untuk dapat dicintai, diterima dan tidak menjadi beban bagi orang lain. Harapan juga berhubungan dengan domain agama/keimanan yaitu harapan untuk bisa masuk ke surga dan berkumpul dengan orangorang terkasih di surga. Harapan dari perspektif yang berbeda akan memiliki makna yang berbeda namun tetap fokus kepada satu hal yaitu tujuan akan masa depan. Harapan merupakan sumber

Astuti, Sujianto, Kusuma / Perkembangan Konsep dan Alat Ukur Harapan dalam ... Page 49 of 51 
Jurnal IImu Keperawatan Medikal Bedah 2 (2), November 2019, 1-51

ISSN 2338-2058 (print), ISSN 2621-2986 (online)

kekuatan utama dari dalam individu yang berhubungan dengan kualitas hidup pasien dan dapat meningkatkan tingkat kesehatan pasien. Berdasarkan model regresi, harapan merupakan faktor prediktor independen yang dapat meningkatkan kualitas hidup yang baik pada pasien PGTA. Konsep harapan merupakan konsep ilmiah yang dapat dijelaskan secara ilmiah dan dapat di ukur, namun harapan bersifat individual dan subjektif. Peningkatan level harapan dapat dipengaruhi oleh faktor spiritual, kepribadian individu sendiri, lingkungan, dukungan sosial keluarga/teman/lingkungan, faktor prognosis kesehatan, tingkat pengetahuan pasien, dan koping individu. Level harapan dapat diukur dengan beberapa alat ukur yang telah dikembangkan antara lain HHI, miller hope scale, adult hope scale, dan lain-lain. Studi ini bermanfaat untuk menambah wawasan perawat mengenai konsep harapan dalam keperawatan terutama pada pasien PGTA. Pengembangan konsep pengkajian harapan dan intervensi keperawatan terkait peningkatan harapan diharapkan dapat berkembang dalam keperawatan.

\section{DAFTAR PUSTAKA}

Abdi, N., \& Asadi-Lari, M. (2011). Standardization of three hope scales, as possible measures at the end of life, in Iranian population. Iranian Journal of Cancer Prevention, 4(2), 71-77. Retrieved

from http://www.ijcp.ir/download.asp?code=IJCP114282\%5Cnhttp://ovidsp.ovid.com/ovidweb.c gi?T $=$ JS\&PAGE $=$ reference $\& D=e m e d 10 \& N E W S=N \& A N=2011255759$

Bahmani, B., Motamed Najjar, M., Sayyah, M., Shafi-Abadi, A., \& Kashani, H.H. (2015). The effectiveness of cognitive-existential group therapy on increasing hope and decreasing depression in women-treated with haemodialysis. Global Journal of Health Science, 8(6), 219. https://doi.org/10.5539/gjhs.v8n6p219

Bayoumi, M., \& Alwakeel, J. (2012). Palliative care \& medicine hemodialysis patients needs priorities according to Maslows' hierarchy and quality of life. Journal of Palliative Care and Medicine, 2(2), 2-6. https://doi.org/10.4172/2165-7386.1000106

Billington, E., Simpson, J., Unwin, J., Bray, D., \& Giles, D. (2008). Does hope predict adjustment to end-stage renal failure and consequent dialysis?. British Journal of Health Psychology. 683-699. https://doi.org/10.1348/135910707X248959

Davison, S. N., \& Simpson, C. (2006). Hope and advance care planning in patients with end stage renal disease: Qualitative interview study. British Medical Journal, 333(7574), 886-889. https://doi.org/10.1136/bmj.38965.626250.55

Ghadam, M. S., Poorgholami, F., Jahromi, Z.B., Parandavar, N., Kalani, N., \& Rahmanian, E. (2015). Effect of self-care education by face-to-face method on the quality of life in hemodialysis patients (relying on ferrans and powers questionnaire). Global Journal of Health Science, 8 (6), 121. https://doi.org/10.5539/gjhs.v8n6p121

Hendricks, C.S., Hendricks, D., Murdaugh, C., Tavakoli, A., Gibbons, M.E., Servonsky, E. J., ... Gilmore, K. J. (2005). Psychometric testing of the Miller Hope Scale with rural southern adolescents. Journal of Multicultural Nursing \& Health, 11(3), 41-50.

Astuti, Sujianto, Kusuma / Perkembangan Konsep dan Alat Ukur Harapan dalam ... Page 50 of 51 
Herth, K. (2014). The concept of hope in nursing 3 : Hope and palliative care nursing The concept of hope in nursing 3: hope and palliative care nursing Kaye A Herth; John R Cutcliffe. (October). https://doi.org/10.12968/bjon.2002.11.14.10470

Hope | Definition of hope in English by Oxford Dictionaries. (n.d.). Retrieved April 12, 2019, from https://en.oxforddictionaries.com/definition/hope

Howell, A. J., \& Larsen, D. J. (2015). Understanding Other-Oriented Hope An Integral Concept Within Hope Studies. New York: Springer International Publishing.

KBBI. (2019). Arti kata harap - Kamus Besar Bahasa Indonesia (KBBI) Online. Retrieved April 12, 2019, from 2019 website: https://kbbi.web.id/harap

Malik, A. M., \& Mazahir, S. (2015). Trust, hope and quality of life in renal failure patient. 27(4), 3493-3498, ISSN 1013-5316; CODEN: SINTE.

Orlandi, F. de S., Pepino, B.G., Pavarini, S.C.I., dos Santos, D.A., \& de Mendiondo, M.S.Z. (2012). The evaluation of the level of hope of elderly chronic kidney disease patients undergoing hemodialysis. Revista Da Escola de Enfermagem, 46(4), 900-905. https://doi.org/10.1590/S0080-62342012000400017

Ottaviani, A.C., Souza, É.N., Drago, N., de Mendiondo, M.S.Z., de Pavarini, S.C.I., \& Orlandi, F. de S. (2014). Hope and spirituality among patients with chronic kidney disease undergoing hemodialysis: a correlational study. Revista Latino-Americana de Enfermagem, 22(2), 248254. https://doi.org/10.1590/0104-1169.3323.2409

Poorgholami, F., Abdollahifard, S., Zamani, M., Jahromi, M.K., \& Jahromi, Z.B. (2015). The effect of stress management training on hope in hemodialysis patients. Global Journal of Health Science, 8(7), 165. https://doi.org/10.5539/gjhs.v8n7p165

Poorgholami, F., Mansoori, P., Montaseri, Z., \& Najafi, K. (2016). Effect of self care education with and without telephone follow-up on the level of hope in renal dialysis patients : a singleblind randomized controlled clinical trial original article. International Journal of Community based Nursing and Midwifery, 4(3), 256-264. https://www.ncbi.nlm.nih.gov/pubmed/27382592\#

Zegarow, P., Jankowska, M., Sańko-Resmer, J., Durlik, M., Grzeszczyk, M., \& Pączek, L. (2014). Kidney transplantation does not increase the level of basic hope or life satisfaction compared with hemodialysis in patients with chronic kidney disease. Transplantation Proceedings, 46(8), 2598-2601. https://doi.org/10.1016/j.transproceed.2014.08.014 